\title{
Analyzing Class Attendance and Student Achievement in Prescribed College Mathematics Courses
}

\author{
Teresa A. Schmidt (Corresponding author) \\ University Studies Department, Middle Tennessee State University \\ PO Box 16, Murfreesboro, TN, United States \\ Tel: 615-898-2208Ｅ-mail: Teresa.Schmidt@mtsu.edu \\ Joan M. Raines \\ University Studies Department, Middle Tennessee State University \\ PO Box 16, Murfreesboro, TN, United States \\ E-mail: Joan.Raines@mtsu.edu
}

Received: August 28, 2019 Accepted: October 9, 2019 Published: November 15, 2019

doi:10.5296/gjes.v5i2.15352 URL: https://doi.org/10.5296/gjes.v5i2.15352

\begin{abstract}
Class attendance has been a concern of educators over the years. Multiple research studies have examined class attendance and its impact on student achievement in various college classes. The purpose of this study was to determine whether a relationship existed between class attendance and student achievement in prescribed college mathematics courses. Class attendance was compared with various factors for students at one institution across multiple sections of two different prescribed mathematics courses, College Algebra and Applied Statistics. Results indicated that the number of days that a student missed class did affect their overall performance in the course. Additionally it was noted that if a student missed more than $40 \%$ of class instructional time, they were certain not to receive a final course grade higher than a D.
\end{abstract}

Keywords: Attendance, Student Achievement, Grades, Academic Success 


\section{Introduction}

For twelve years many students got up and rode a big yellow school bus off to meet the world of learning and education, then a new world of learning opened up. One with both freedom and responsibility. While attendance is mandatory for a K-12 education, post-secondary education does not come with such stipulations. If you were to ask any educator about the relationship between student attendance and their academic performance in class, many would agree that academic performance in college classes could be directly impacted by a student's attendance or lack thereof. Much of the research focuses on class attendance and its impact on student achievement; however, there are additional confounding variables that can directly impact a student's performance in class, i.e. work schedule, student autonomy, motivation, and stress (Credé, Roch, \& Kieszczynka, 2010). Several articles have been written regarding class attendance and its impact on student achievement. The research suggests that students with "high attendance achieve higher academic performance in both coursework and examinations than students with poor attendance" (Nyamapfene, 2010, p. 64). The purpose of this study was to determine whether there is a relationship between class attendance and student achievement in prescribed college mathematics courses. Prescribed mathematics courses are special sections of their equivalent college level mathematics courses that contain additional content addressing deficiencies that may hinder successful completion of the respective courses. The prescribed mathematics courses examined in this paper are College Algebra and Applied Statistics.

\section{Brief Review of Literature}

\subsection{Attendance and Student Success}

Many educators hold the belief that class attendance is associated with or a predictor of better grades in class. Indeed, many research studies (Romer, 1993; Hancock, 1994; Moore, 2003; Teixeira, 2014) have examined the relationship between class attendance and students' academic performance and most conclude that consistent class attendance strongly correlates with academic performance.

Gump (2005) analyzed final grades and class attendance of three hundred undergraduates over four semesters in an Introduction to Japanese Culture class. Class size was approximately twenty-five students, and he looked at attendance at weekly discussion sections only. The absences he included in the study were only those that were considered to be unexcused. Gump found a negative correlation between absences and final grades in the course, with all correlations being statistically significant. He concluded that, "on average, students with fewer absences did better overall" (p. 22). LeBlanc (2005) found similar results in his study of 1617 students at four institutions over a fourteen-year period. Students were in some type of public speaking or communications class and attendance was recorded in every class. LeBlanc's results revealed a strong negative correlation between the number of absences and the end of course grade. Additionally, the relationship between attendance and grades did not change whether there was an enforced attendance policy or not.

In their meta-analysis on class attendance in college, Credé, Roch, and Kieszczynka (2010) 
found the relationship between class attendance and grades revealed that attendance had a strong relationship with both class grades and GPA. They concluded that attendance was "a better predictor of college grades than any other known predictor of academic performance, including scores on standardized admissions tests such as the SAT, high school GPA, study habits, and study skills" (p. 272). Credé et al. suggested that students' grades could improve significantly if class attendance increased.

Lukkarinen, Koivukangas, and Seppälä (2016) assessed the relationship between attendance and the performance of 86 students in a masters level methodology course at a Finnish university. Attendance at lectures and exercise sessions was not mandatory, and attendance was taken by having students sign an attendance sheet. Students were placed in one of three subgroups based on attendance, and exam points were used to indicate a student's performance in the course. The researchers found there was a positive correlation between exam points and attendance. For the group of students who participated in lectures, their attendance was a significant predictor of their performance in the course. Nyamapfene (2010) also examined the impact of attendance on academic performance in an electronics engineering course that had no mandatory attendance policy. The course consisted of 20 one-hour lecture classes with online lecture notes available to students prior to class time. After examining correlation values between academic performance and lecture attendance, the associated p-value confirmed the statistical significance of the values. This implied that class attendance did affect student performance, even when students had access to online lecture notes. Additionally, Nyamapfene noticed significant decreases in attendance at certain periods during the semester. He discovered these decreases coincided with submission deadlines for students' work in other courses.

In a study of students from three Texas community colleges, Zientek, Ozel, Fong, and Griffin (2013) investigated several factors that affected the success of students in developmental mathematics courses. Their sample consisted of 382 students enrolled in algebra and intermediate algebra courses with 19 different instructors. Each college had their own attendance policies, which varied from college to college. Multiple regression results revealed that whether or not a college had an attendance policy, attendance was the best predictor of the final course grade. Albert, Zientek, and Manage (2018) also examined the importance of class attendance on student success in developmental mathematics classes. The study consisted of 343 students in the highest level of developmental mathematics offered at a state university from fall 2012 through spring 2015. The university did not have a mandatory attendance policy, but students could not drop the course and the instructor was strict with their own attendance policy. Albert, Zientek, and Manage's study provided evidence that passing the course was predicted by attendance. Furthermore, their findings did show that without a strict attendance policy, absenteeism gradually increased and absence rates began to increase after the first exam.

\subsection{Attendance Policies}

Unlike the mandatory attendance policies from the elementary grades through high school, most college classes do not have attendance policies. Research on the effects of attendance 
policies on student success have yielded mixed results. Shimoff and Catania (2001) recorded attendance for 57 students in an introductory psychology class at the University of Maryland and kept no record of attendance for the other 57 students in the class. The researchers found that the students whose attendance was recorded attended class more often. Their absence rate decreased by one third, which was statistically significant. Additionally, these same students performed significantly better on quizzes than the students whose attendance was not recorded. Shimoff and Catania concluded that by just recording attendance, both class attendance and overall academic performance increased. Moore (2005) examined how students' grades and attendance rates in an introductory biology course were affected by penalties for excessive absences and by additional emphasis given to the importance of attending class. His study, conducted at a special-admissions university in the Midwest, involved 684 developmental education students in four sections of the course. Attendance was recorded at every class meeting and no incentives were given for attending class. Students either received no additional emphasis on attendance and no penalties for absences, no additional emphasis on attendance and penalties for absences, additional emphasis on attendance and no penalties for absences, or additional emphasis on attendance and penalties for absences. Moore's results indicated that students in the sections where attendance was emphasized came to class more often and had higher grades than the students in the sections where no additional emphasis was placed on attendance. Penalties for absences had no effect on attendance or grades.

When comparing two sections of an economics course, one with an attendance policy and one without, Marburger's (2006) research revealed significant differences in student attendance between the two sections. As the semester progressed, the absence rate for students in the class without an attendance policy continually increased while the absence rate in the class with an attendance policy remained constant. Marburger noted that "whereas the relationship between a mandatory attendance policy and learning is statistically significant, the impact does not appear to be substantial" (p. 154).

Chenneville and Jordan (2008) investigated the impact that having a graded attendance policy would have on student attendance. The participants in their study consisted of 155 undergraduates in eight psychology courses at a public university. The different classes were divided into two groups - the experimental group where the courses had a graded attendance policy and the control group that had no attendance policy. A sign-in sheet was used during each class meeting to record attendance for both groups. A t-test revealed a significant difference between the two groups, which indicated that a graded attendance policy increased class attendance. Chenneville and Jordan concluded that "having a graded attendance policy may serve as a motivator for increasing class attendance" (p. 33).

Multiple regression results in Zientek et al.'s (2013) study indicated that attendance policies were needed in all of the developmental mathematics courses. They found that for some students, having an attendance policy might have been the motivation needed for students to attend class. However, for attendance policies to be effective, all instructors have to implement and follow them. 
Some studies have indicated that having a mandatory attendance policy would have little to no effect on academic performance, and in some cases could actually hinder learning. Hyde and Flournoy (1986) analyzed the class attendance of second-year medical students at the University of Oklahoma College of Medicine and concluded that there were students who could independently master the material and perform as well as those attending lectures. These researchers felt that having a mandatory attendance policy could in fact hinder some students' learning and academic performance. Credé, Roch, and Kieszczynka's (2010) meta-analysis revealed some support for the hypothesis that students in classes with mandatory attendance policies had higher grades than students in classes without those policies. There was a small positive effect on average grades when there were mandatory attendance policies in place. However, this finding could not make an argument in favor of having mandatory attendance policies.

Faculty in higher education have varying opinions regarding class attendance policies. Some believe attendance should be mandatory while others believe students should be able to make their own decisions about attending class. From the existing research, it is not clear if mandatory attendance policies affect student achievement or not.

\section{Background of Study}

\subsection{Purpose}

Many incoming college students are at risk for academic failure. A high percentage of the students enter school unprepared for college-level mathematics and are required to complete prescribed mathematics courses. The mathematics courses used in this study are prescribed mathematics courses, which means students are required to take one or more of these courses based on their math ACT scores and/or placement testing. Since students in these courses require enhanced content, the link between class attendance and their academic performance is important to investigate.

The purpose of this study was to compare students' class attendance and their grades in prescribed mathematics courses to determine if there was a correlation between class attendance and academic performance. The findings of the study may provide insights into better approaches to use with this group of students, and might be able to be generalized to other populations of students taking different mathematics courses. If class attendance in these courses is strongly related to student performance, then this can also provide instructors with valuable evidence that might persuade a larger proportion of students to attend class.

\subsection{Institutional Setting}

This study was conducted at a public four-year university in the mid-south. The institution is classified as a Carnegie R3 university with a student population in fall 2018 of 21630 (19 251 undergraduates and 2379 graduates). The student body is $36 \%$ female and $42 \%$ male, with $22 \%$ unreported. The average ACT composite score for students attending the university fall 2018-spring 2019 was 22.1 with an average math score of 21.0. There were 1275 freshmen with math ACT scores between 11 and 20 (6.4\% between 11 and 15 and $37.6 \%$ between 16 and 20). 


\section{Methodology}

\subsection{Participants and Course Attendance Policies}

Any student admitted to the university not achieving a minimum math ACT score of 19 is required to take a prescribed mathematics course; however, any student may elect to verify placement in the course though university assessment using the Accuplacer exam. Prescribed mathematics courses are special sections of their equivalent college level mathematics courses that contain additional content addressing deficiencies that may hinder successful completion of the respective courses. Enrollment in these courses is usually capped to maintain a low student/teacher ratio. Once students successfully complete the prescribed course, they receive college level credit. At the university, faculty have the option of using a plus/minus grade scale or the standard grading scale where 90-100 is an A, 80-89 is a B, 70-79 is a C, 60-69 is a D, and anything below 60 is an F. For the prescribed mathematics courses, plus/minus grading is not allowed and the standard grade scale is used.

The participants in this study included all students for whom records were kept and who took the final exam and completed the course. Data for students who withdrew or did not take the final exam were omitted. The participants were students who were enrolled in prescribed sections of either College Algebra or Applied Statistics over seven semesters (from spring 2015 through spring 2018). There were 27 sections of College Algebra $(\mathrm{N}=453)$ and 9 sections of Applied Statistics $(\mathrm{N}=168)$. Of the 621 students in the study, there were 277 males (approximately 45\%) and 344 females (approximately 55\%) enrolled in the prescribed courses. Means, medians, and standard deviations for homework, test grades, final exam grades, and final course grades for the prescribed mathematics courses in the study are shown in Table 1.

Table 1. Descriptive statistics

\begin{tabular}{lccc}
\hline & Mean & Median & Standard Deviation \\
\hline Homework & 77.23 & 85.80 & 23.87 \\
Test Grades & 79.74 & 81.50 & 13.80 \\
Final Exam Grades & 68.34 & 69.30 & 15.55 \\
Final Course Grades & 77.61 & 78.74 & 12.82 \\
\hline
\end{tabular}

While the university does not have a compulsory attendance policy, attendance is required for prescribed courses and instructors are expected to keep a record of attendance for all students. Attendance in the class sections in this study was taken at every class meeting and recorded either by calling or visually taking roll or by using a sign-in sheet. For the purpose of this study, no distinction was made in the type of student absence - excused or unexcused.

\subsection{Course Information}

The study concerned two prescribed mathematics courses, College Algebra and Applied 


\section{Macrothink}

Global Journal of Educational Studies

ISSN 2377-3936

2019, Vol. 5, No. 2

Statistics. All sections of the four-credit hour courses were taught by the same two instructors in a similar manner (e.g., the same departmental syllabus, textbook, sequence of topics, pedagogical techniques, and departmental final exam). The study included 621 students possessing math ACT scores from 15 to 18. All exams covered material presented both in class and in graded online homework assignments. Missing classes for any reason did not preclude any student from earning an A. No grades were "curved", and there were no extra-credit projects. Additionally, neither incentives nor penalties were given for attendance or nonattendance. Final course grades were based entirely on students' mastery of the course content. The grade distribution for each course and the combined grade distribution is shown in Table 2.

Table 2. Final course grade for college algebra and applied statistics

\begin{tabular}{ccc}
\hline Final Course Grade & Frequency & Percent \\
\hline College Algebra & & \\
A & 90 & 19.9 \\
B & 129 & 28.5 \\
C & 130 & 28.7 \\
D & 61 & 13.5 \\
F & 43 & 9.4 \\
Applied Statistics & & \\
A & 22 & 13.0 \\
B & 43 & 25.6 \\
C & 56 & 33.4 \\
D & 27 & 16.1 \\
F & 20 & 11.9 \\
Combined & & \\
A & 112 & 18.0 \\
B & 172 & 27.7 \\
C & 186 & 30.0 \\
D & 88 & 14.2 \\
F & 63 & 10.1 \\
\hline
\end{tabular}

\subsection{Data Analysis}

This study was a retrospective study examining whether there was a relationship between class attendance and student achievement in prescribed college mathematics courses from spring 2015 through spring 2018. The data were analyzed to determine if the number of class meetings per week, the instructor, or the course (College Algebra or Applied Statistics) was a factor. For each of these three factors (class meetings per week, instructor, and the course), a two-sample independent t-test was used to determine if the percent of days absent was a significant difference for each of the factors. Based on the results of these analyses, an 
appropriate simple linear regression model was developed to assess if the overall course grade could be modeled by the percent of days absent. Additionally, other potential factors were examined to see if they contributed to the strength of the model.

\section{Results and Discussion}

\subsection{Factors Analyzed}

As previously stated, the researchers began by examining if the percentage of absences was a statistically significant difference for any of the three identified factors. In order to make a comparison for absences among the two- and three-day a week classes, the percent of days absent was used instead of the number of absences. Table 3 shows how the number of days absent translates to the percentage of absences for courses meeting three days per week versus two days per week.

Table 3. Comparison of percent days missed

\begin{tabular}{ccc}
\hline & $\begin{array}{c}\text { Three-day per week } \\
\text { 40 instructional days }\end{array}$ & $\begin{array}{c}\text { Two-day per week } \\
\text { 27 instructional days }\end{array}$ \\
\cline { 2 - 3 } Percent of days absent & Number of days absent & Number of days absent \\
\hline 0 to 5\% & $0-2$ & $0-2$ \\
5 to $10 \%$ & $2-4$ & $2-3$ \\
10 to $15 \%$ & $4-6$ & $3-5$ \\
15 to $20 \%$ & $6-8$ & $5-6$ \\
20 to $25 \%$ & $8-10$ & $6-7$ \\
25 to $30 \%$ & $10-12$ & $7-9$ \\
30 to $35 \%$ & $12-14$ & $9-10$ \\
35 to $40 \%$ & $14-16$ & $10-11$ \\
$40 \%$ and above & $16-40$ & $11-27$ \\
\hline
\end{tabular}

Note. Days absent for two-day per week classes were rounded to the nearest day.

A two-sample independent t-test was performed to determine if the percent of days absent was different for the course meeting three-days versus two-days a week. There was no significant difference in the three-day a week $(\mathrm{M}=9.81 \%, \mathrm{SD}=10.28)$ and the two-day a week $(\mathrm{M}=10.48 \%, \mathrm{SD}=10.80)$ classes; $\mathrm{t}(619)=.767, \mathrm{p}=.444$. These results indicate that the number of class meetings per week had no effect on the percent of days absent a student procured during a semester.

Given that the study consisted of two instructors, the data was also analyzed to determine if there was any teacher effect. A two-sample independent t-test was conducted to compare the percent of days absent to determine if there was a significant difference among the two instructors. The analysis determined that there was a significant percent absent average difference between the two instructors (MDiff= 2.4, SED =0.9); $\mathrm{t}(619)=2.724, \mathrm{p}=.007$. However, on closer examination of the percent of days absent, it was determined that one of 
the professors had $1 \%$ to $4 \%$ more absences than the other. Table 3 shows that $4 \%$ of days absent is less than two days absent in either a two- or three-day a week class. The researchers believe that this is not considered to be practically significant. This is in agreement with prior research conducted by Silvestri (2003).

A two-sample independent t-test was also conducted to compare the percent of days absent and the course (College Algebra or Applied Statistics). Upon analyzing the data, there was a significant difference found between College Algebra $(\mathrm{M}=9.26, \mathrm{SD}=9.61)$ and Applied Statistics $(\mathrm{M}=12.14, \mathrm{SD}=12.45) ; \mathrm{t}(244.5)=2.705, \mathrm{p}=.007$. However, further analysis revealed that the percent of days absent determined for Applied Statistics students were between approximately $1 \%$ and $4.9 \%$ more absences than College Algebra students. Again, while the percent of days absent is statistically significant, closer examination revealed that this was at most two days absent (see Table 3) in either a two- or three-day a week class and likewise, the researchers do not believe this to be practically significant. This is in agreement with prior research conducted by Silvestri (2003).

\subsection{Linear Regression}

Because the difference in the percent of days absent was either not statistically significant or practically significant for the number of class meetings per week, the instructor, and the course (College Algebra or Applied Statistics), all class data were combined for the subsequent analysis. Using simple linear regression, the data were examined for a relationship between the final course grade based on the percent of days absent.

The simple linear regression was calculated to predict final course grade based on percent of days absent. A significant regression equation showed $(\mathrm{F}(1,619)=179.958, \mathrm{p}<.000)$, with an adjusted $\mathrm{R}^{2}$ of 0.224 , students' average predicted final course grade is equal to $83.14+-.578$ percent of days absent. The regression revealed that $22 \%$ of the variation in the final course grade could be explained by the percent of days absent. Additionally, for each additional 10\% of classes missed (approximately four days), one could expect students' average final course grade to decrease by approximately half $(6 \%)$ a letter grade.

Final course grade data were then analyzed using linear regression for other possible contributing factors such as those identified in Table 1, as well as gender and course type. Of these variables, only homework was found to impact students' final course grade. A simple linear regression was calculated to predict final course grade based on the percent of days absent and homework. A significant regression equation was found $(F(2,618)=219.642$, $\mathrm{p}<.000$ ), with an adjusted $\mathrm{R}^{2}$ of .414 . The corresponding model indicates that students' predicted average final course grade is equal to $60.309+-0.304$ percent of days absent +0.264 homework. The regression revealed that $41 \%$ of the variation in a student's final course grade could be explained by combining the percent of days absent with a student's homework grade. Both were significant predictors of a student's final course grade (percent of days absent: $\mathrm{t}(618)=-7.221, \mathrm{p}<.000$; homework: $\mathrm{t}(618)=14.181, \mathrm{p}<.000)$. No other variables were revealed through regression to be of statistical significance. Further analysis of the data using frequencies and the regression equation did illustrate the fact that if a student was absent more than $40 \%$ of the class instructional time, regardless of the course or number 
of days the class met, they were certain not to receive a final course grade higher than a D.

As with most studies, there were a few limitations. Since data were drawn from a single institution, the results may have limited generalizability. The classes in the study met on different days of the week and at different times of the day, but students were in class the same amount of time each week. However, differences could occur due to the amount of time students spent in each class meeting or due to the time of day the class met. This could also have had an effect on class attendance. The same two instructors taught all of the class sections in the study. Although results found there was no significant difference among the instructors, the findings may not be generalizable to other faculty due to differences in pedagogy or teaching strategies. Since placement testing is optional, students could have been placed in the wrong course based on math ACT scores alone. This could explain why some students never missed a class and still failed the course or had excessive absences and made an A. While students in prescribed mathematics courses have math ACT scores ranging from 15 to 18 , that data was not available for use in this study. If access to these scores had been obtained, it might have helped explain some of the variation in the grade distribution. Finally, the classes examined for this study typically had a class size average of 20 students, thus this study may not be applicable to larger class sizes. Despite the limitations, the study highlights the relationship between class attendance and academic performance.

\section{Conclusions and Recommendations}

The purpose of this study was to compare students' class attendance and their final course grades in prescribed mathematics courses to determine if there was a correlation between class attendance and academic performance. Based on our findings, there was determined to be an overall trend that students with a high percent of days absent will incur a lower final course average. It is relevant to mention that there are additional contributing secondary factors beyond attendance (i.e. work schedule, student autonomy, motivation, and stress) that affect a student's grade.

Prior research has found that class attendance is a significant and positive predictor of course grades, and that attendance is the most accurate predictor of academic performance. In fact, dramatic improvements in grades could be achieved if attendance rates could be increased. This study does not dispute these findings. In reality, this study highlights the fact that attendance has an impact on a student's final course grade in prescribed mathematics courses. To this end, this research serves to inform instructors regarding the impact absences have on student's overall class performance and final grade. College students have many contributing factors impacting their class performance. However, this study agrees with others that as a student incurs increasing absences during the course of a semester the impact is an overall decrease in their final course grade.

Future studies could investigate how well the results would still hold if there were mandatory attendance policies in place. In addition, studies could examine what effect giving points for attendance would have on attendance rates and student learning and achievement. Future studies could also address other factors that could influence attendance such as personal motivation, family circumstances, or whether students were working or not. 


\section{References}

Albert, J., Zientek, L., \& Manage, A. (2018). Attendance: Case-study in developmental mathematics classrooms. Journal of College Reading and Learning, 48(3), 175-188. https://doi.org/10.1080/10790195.2018.1472941

Chenneville, T., \& Jordan, C. (2008). Impact of attendance policies on course attendance among college students. Journal of the Scholarship of Teaching and Learning, 8(3), 29-35.

Credé, M., Roch, S. G., \& Kieszczynks, U. M. (2010). Class attendance in college: A meta-analytic review of the relationship of class attendance with grades and student characteristics. Review of Educational Research, 80(2), 272-295. https://doi.org/10.3102/0034654310362998

Gump, S. E. (2005). The cost of cutting class: Attendance as a predictor of student success. College Teaching, 53(1), 21-26. https://doi.org/10.3200/CTCH.53.1.21-26

Hancock, T. M. (1994). Effects of mandatory attendance on student performance. College Student Journal, 28(3), 326-329.

Hyde, R. M., \& Flournoy, D. J. (1986). A case against mandatory lecture attendance. Journal of Medical Education, 61, 175-176. https://doi.org/10.1097/00001888-198603000-00005

LeBlanc, H. P. (2005, April). The relationship between attendance and grades in the college classroom. Paper presented at the $17^{\text {th }}$ Annual Meeting of the International Academy of Business Disciplines, Pittsburgh, PA. Retrieved from http://communication.utsa.edu/leblanc/articles/art31.pdf

Lukkarinen, A., Koivukangas, P., \& Seppälä, T. (2016). Relationship between class attendance and student performance. Procedia-Social and Behaviorial Sciences, 228, 341-347. https://doi.org/10.1016/j.sbspro.2016.07.051

Marburger, D. R. (2006). Does mandatory attendance improve student performance? The Journal of Economic Education, 37(2), 148-155. https://doi.org/10.3200/JECE.37.2.148-155

Moore, R. (2003). Attendance and performance: How important is it for students to attend class? Journal of College Science Teaching, 32(6), 367-371.

Moore, R. (2005). Attendance: Are penalties more effective than rewards? Journal of Developmental Education, 29(2), 26-32.

Nyamapfene, A. (2010). Does class attendance still matter? Engineering Education, 5(1), 64-74. https://doi.org/10.11120/ened.2010.05010064

Romer, D. (1993). Do students go to class? Should they? Journal of Economic Perspectives, 7(3), 167-174. https://doi.org/10.1257/jep.7.3.167

Shimoff, E., \& Catania, A. C. (2001). Effects of recording attendance on grades in introductory psychology. Teaching of Psychology, 28(3), 192-195. https://doi.org/10.1207/S15328023TOP2803_04 
Silvestri, L. (2003). The effect of attendance on undergraduate methods course grades. Education, 123(3), 483-486.

Teixeira, A. A. C. (2014). The impact of class absenteeism on undergraduates' academic performance: evidence from an elite economics school in Portugal. Innovations in Education and Teaching International, 53(2), 230-242. https://doi.org/10.1080/14703297.2014.937730

Zientek, L. R., Yetkiner Ozel, Z. E., Fong, C. J., \& Griffin, M. (2013). Student success in developmental mathematics courses. Community College Journal of Research and Practice, 37(12), 990-1010. https://doi.org/10.1080/10668926.2010.491993

\section{Copyright Disclaimer}

Copyright for this article is retained by the author(s), with first publication rights granted to the journal.

This is an open-access article distributed under the terms and conditions of the Creative Commons Attribution license (http://creativecommons.org/licenses/by/3.0/). 